\title{
Encapsulation and Co-Precipitation Processes with Supercritical Fluids: Applications with Essential Oils
}

\author{
Ángel Martín, Salima Varona, Alexander Navarrete and María José Cocero* \\ High Pressure Processes Group. Department of Chemical Engineering and Environmental Technology. University of
Valladolid Facultad de Ciencias, Prado de la Magdalena s/n 47011 Valladolid, Spain
}

\begin{abstract}
Essential oils have important commercial applications as preservatives and flavours, and more recently as natural antimicrobial agents. These applications require a suitable formulation constituted by biodegradable compounds that protect the essential oil from degradation and evaporation at the same time that allows for a sustained release. Microcapsules of biopolymers loaded with essential oils meet these requirements. Such microcapsules can be prepared with different processes such as spray-drying, freeze-drying and coacervation, and supercritical fluids are an advantageous medium for this purpose. Some supercritical fluid-based precipitation processes have already been applied to produce these microcapsules. Amongst them, the results obtained with Particles from Gas Saturated Solutions (PGSS), PGSS-drying and Concentrated Powder Form (CPF) processes are particularly promising. Recent developments in the preparation of formulations with supercritical fluids include the preparation of liposomes and micelles, which can be suitable carriers for essential oils.
\end{abstract}

Keywords: Supercritical carbon dioxide, spray drying, emulsion, particles from gas saturated solutions, concentrated powder form, micelle, liposome.

\section{INTRODUCTION}

Essential oils are the ethereal fraction obtained by physical means from a plant. Nowadays, their main uses are in perfume and flavour industries although they are also used in food and pharmaceutical industries as preservatives (mainly antioxidants) and flavours, for applications like cosmetics and personal care products, pharmaceutical products, insecticides, preparations for paints or textile industries, additives for rubber and plastics or adhesives [1]. More recently, many applications of essential oils as natural antimicrobial agents have been described. Compounds in essential oils with phenolic structure have been identified to be active against microorganisms [2, 3]. Burt [4] has selected some plants that can be used in food industry owing to their antibacterial properties: cilantro, coriander, cinnamon, oregano, rosemary, sage, clove and thyme. Table 1 shows some reported applications of essential oils [5-26].

Essential oils are sensitive materials which can easily suffer degradation under the action of oxygen, light and moderate temperatures. Furthermore, they are insoluble in water, and for certain applications a controlled release is required. Therefore an adequate formulation of the essential oil which takes into account these aspects is required for commercial applications. Common goals in the development of essential oil formulations are to protect the essential oil from degradation or from losses by evaporation, to achieve a controlled release, and to facilitate handling. Possible formu-

*Address correspondence to this author at the High Pressure Processes Group. Department of Chemical Engineering and Environmental Technology. University of Valladolid Facultad de Ciencias, Prado de la Magdalena s/n 47011 Valladolid (Spain); Tel: +34 983423174; Fax: +34 983423013; E-mail: mjcocero@iq.uva.es lations include liquid forms (emulsions, micelles, liquid solutions etc.), semi-liquid forms (gels, liposomes etc.), and solid forms (microcapsules or microcomposites).

Essentials oils exist in liquid form at room temperature. Therefore the simplest form of encapsulation consists in emulsifying or dispersing the components in an aqueous solution. The main drawback of this formulation is the handle difficulty. This problem can be overcome by producing a dry formulation by microencapsulation, entrapping the oil drops in a carrier material.

Encapsulation techniques can be divided into three classes: chemical processes like molecular inclusion or interfacial polymerization, physicochemical techniques like coacervation and liposome encapsulation and physical processes like spray drying, spray chilling/cooling, co-crystallization, extrusion or fluidized bed coating. The use of supercritical fluids as an alternative medium for formulating essential oils can improve the results obtained with other physical or physicochemical techniques, or even make possible innovative formulations, due to the peculiar properties of supercritical fluids in general and of supercritical carbon dioxide in particular (adjustable solvent power, favourable transport properties, no contamination of the product) which are significantly different from those of gas and liquid solvents [27]. The objective of this review is to provide an account of the principal technologies used for encapsulation of essentials oils, and to present innovative applications of supercritical fluids in this field.

\section{COATING MATERIALS}

The coating or carrier material plays an important role because it is responsible for the protection of the oil and for enabling a controlled release. This material must be selected 
Table 1. Reported Applications of Essential Oils

\begin{tabular}{|c|c|c|}
\hline Essential Oil & Application & Ref. \\
\hline Artemisia afra, Pteronia incana oils, Lavandula officinalis, and Rosmarinus officinalis & Preservatives in aqueous cream formulation & [5] \\
\hline Australian tea tree oil & Recurrent herpes labialis & [6] \\
\hline Basil & Tratment for acne & [7] \\
\hline Blend of the spices Capsicum, Cinamon, anise and oregano oil & Feed complement for piglets & [8] \\
\hline Chamomile & Treatment of inflammatory dermatoses & [9] \\
\hline Chamomile & $\begin{array}{l}\text { Insect bite, dry skin, sunburn, acne and pso- } \\
\text { riasis }\end{array}$ & [10] \\
\hline Cinnamon, clove & Yoghurt conservation & [11] \\
\hline $\begin{array}{c}\text { Cinnamomum zeylanicum (cinnamon), Mentha piperita (peppermint), Ocimum basilicum } \\
\text { (basil), Origanum vulgare (origanum), Teloxys ambrosioides (the flavoring herb epazote), } \\
\text { Syrygium aromaticum (clove), and Thymus vulgaris (thyme) }\end{array}$ & Inhibition of fungal development in Maize & [12] \\
\hline $\begin{array}{l}\text { Cinnamon bark (Cinnamomum zeylanicum), lemongrass (Cymbopogon flexuosus), savory } \\
\text { (Satureja montana), Roman chamomile (Chamaemelum nobile), rosewood (Aniba ro- } \\
\text { saeodora), spearmint (Mentha spicata) and tea tree (Melaleuca alternifolia) }\end{array}$ & Selected Bacteria, Fungi and Viruses & [13] \\
\hline Cymbopogon citratos & Inhibitor of storage fungi & [14] \\
\hline Eucalyptus citriodora, Eucalyptus hybrida and Ocimum basilicum & Nematicidal activity & [15] \\
\hline Laurus nobilis, Eucalyptus globulus and Salvia officinalis & $\begin{array}{l}\text { Preservatives in O/W skin cream, a hydrogel } \\
\text { and a non-alcoholic hydrolyte }\end{array}$ & [16] \\
\hline Lavender & $\begin{array}{l}\text { Bites, stings, boils, burns, stretch marks, } \\
\text { rashes, spots, cold sores, sunburns }\end{array}$ & [17] \\
\hline Lavender & Allergies & [18] \\
\hline Lemongrass & Storaged grain protection & [19] \\
\hline Oregano & Fish food conservation & [20] \\
\hline Oregano and Thyme & $\begin{array}{c}\text { Staphylococcus aureus and Salmonella ty- } \\
\text { phimurium }\end{array}$ & [14] \\
\hline Pyrethrum and neem & Pesticides & [21] \\
\hline Rosemary, sage & Comercial food preservative & [22] \\
\hline Tea tree oil and eucalyptus oil & Herpes simplex virus type 1 & [23] \\
\hline Thyme & Nosema disease in honeybees & [24] \\
\hline $\begin{array}{l}\text { Thyme (Thymus vulgaris L.), Oregano (Origanum vulgare ssp. Hirtum), Clove (Syzygium } \\
\text { aromaticum), nutmeg (Myristica fragrans), black pepper (Piper nigrum L.), geranium (Pelar- } \\
\text { gonium graveolens) }\end{array}$ & Gram positive and Gram negative Bacteria & [25] \\
\hline Vetiver essential oil & Protection of wood against Termites & [26] \\
\hline
\end{tabular}

depending on the specific oil to be coated and the desired characteristic of final microcapsules. Ideally, the coating material should be soluble in water, biodegradable, form low viscosity solutions, yield powders with specific properties (non-hygroscopic, non-porous, soluble, stable, etc.), have a low cost and be easy to dry and non reactive.

In applications with supercritical fluids the properties of the coating material and particularly the interactions of coating materials with supercritical fluids are especially important. It is well known that supercritical carbon dioxide interacts with many polymeric materials, causing several impor- tant variations in their physical properties such as swelling, reduction of cristallinity or reduction of melting and glass transition temperatures [28, 29]. These interactions may be important for enabling the incorporation of essential oils into carrier materials, for example by facilitating the diffusion of the essential oil due to the swelling and opening of the pores of carrier material particles.

Different coating materials have been used in encapsulation techniques, including gums, starches, gelatines and polymers. Most commonly used wall materials for essential oil encapsulations are octenyl succinic anhydride (OSA) 
starches, $\beta$-cyclodextrines, acacia gums, maltodextrines and its mixtures. Recently chitosan and phospholipids have been used as coating materials as well.

Acacia gum is widely used because it presents favourable properties as emulsifier [30]. However, it is expensive, it suffers supply shortages and acacia gum capsules present a limited protective capacity against oxidation because they act as semi permeable membranes. The use of mixtures of gum and maltodextrines results in good relation between price and efficiency [31].

Hydrolysed and chemically modified starches (OSAstarches) are less expensive, very soluble in water, with adequate heat tolerance, and OSA-starch solutions have moderate viscosities [32]. OSA-starches can be effectively used to form an essential oil-in-water emulsion, which can be then dried to produce microcapsules [33].

$\beta$-cyclodextrines are enzymatically modified starches shaped like a hollow cone, which had been widely used for encapsulation of essential oils giving some of the highest encapsulation yields, due to the formation of inclusion complexes between the oil and the apolar cavity of cyclodextrines [34]. The inclusion complex protects the oil efficiently during storage but it has low thermal stability [31].

Chitosan is a natural linear biopolyaminosaccharide, biodegradable, biocompatible, mucoadhesive and its production is economically feasible (chitin is the second most abundant polymer in the nature after cellulose). For these reasons it had been widely used in medicine applications, and it is also suitable for essential oil formulations $[35,36]$.

Phospholipids (phosphatidylcholines, phosphatidylserines and phosphatidylethanolamines) are a class of amphiphilic lipids formed by a hydrophilic head (a phosphate group, a diglyceride and a simple organic molecule) and a hydrophobic tail (long fatty acid), which spontaneously form liposomes, bilayer sheets, micelles, or n-lamellar structures, depending on hydration and temperature. Liposomes can encapsulate hydrophilic compounds in the aqueous internal cavity, and hydrophobic substances can be dissolved into the membrane. Because of their ease of biodegradation and their similarity to cell biomebranes, they are less toxic than polymer or other wall materials and they are excellent carrier systems for a variety of applications, and in particular for essential oils [37, 38].

\section{FORMULATION OF ESSENTIAL OILS BY TECH- NIQUES NOT BASED ON SUPERCRITICAL FLUIDS}

\subsection{Spray-Drying}

Microencapsulation by spray-drying is one of the oldest encapsulation methods, as well as one of the most common and cheapest techniques for producing microcapsules. In this method, the material for encapsulation is homogenized with the carrier material at different ratios. Then the mixture is fed into a spray dryer and atomized with a nozzle or spinning wheel. The contact between drop and hot air takes place during atomization. Rapid evaporation of solvent (usually water) maintains droplet temperature at low level and allows quasi-instantaneously entrapping the active compound. The microcapsules are then collected after they fall to the bottom of the drier [39]. The liquid feeding the sprayer can be a so- lution, an emulsion or a suspension. The main factors in spray-drying that must be optimized are feed temperature, air inlet temperature, and air outlet temperature [40].

Morphology of final product is related to drying conditions. Furthermore the key mass transport phenomenon in the spray drying process is the drying of individual atomized droplets in the chamber. Evaporation stages and heat and mass transfer in spray drying can be described through the evolution of drying rates, as it was suggested by AlamillaBeltran [41]. Five stages of drying were proposed by Dolinsky [42], which are heating from its initial temperature to the equilibrium evaporation temperature, equilibrium evaporation, crust formation, boiling period and bound moisture removal period.

Spray drying is widely used for the drying of heatsensitive food, pharmaceuticals and other substances such as essential oils. Applications of spray-drying for encapsulating essential oils are reviewed in Table 2 [43-60]. Typical encapsulation materials used with essential oils are acacia gum, maltodextrins, hidrophobically modified starches, proteins and mixtures of thereof.

\subsection{Other Techniques}

Different techniques have been successfully used for preparing essential oil-loaded microcapsules. Two of the most successful methods apart from spray drying are freezedrying and coacervation. Other techniques such as annularjet or spinning-jet drying can be used to produce particles loaded with liquids such as essential oils. Table 3 shows some applications of these techniques for essential oil formulation [34-38, 61-75].

In the freeze-drying process solvent is removed from a frozen solution by vacuum sublimation, maintaining the drying chamber pressure and temperature bellow the triple point of solvent. Freeze drying appears as one of the most suitable methods for dehydration of almost all heat-sensitive materials and aromas, due to the lower operating temperatures, slow drying rate and to the use of vacuum. This technique has also been used to encapsulate essentials oils [37, 61].

Coacervation consists in the separation of a polymeric solution into two liquid phases, a polymer-rich phase called coacervate and diluted phase called equilibrium solution, induced by media modifications $(\mathrm{pH}$, ionic strength and polyion concentrations), followed by the coating of the coacervate phase around suspended core particles or suspended droplets. Complex coacervation is based on electrostatic interactions between two oppositely charge polyions in aqueous media, in which the core material in dispersed form is added to the polymer solution. This mixture is then suspended in an aqueous solution phase containing a surfaceactive agent. Finally, solidification of the coating is achieved by thermal, cross-linking or desolventization techniques. Another closely related technique is the organic phase separation, which can be considered as a reversed simple coacervation: a polymer phase separates and deposits on a core that is suspended in an organic solvent rather than in water Several essentials oils were encapsulated by coacervation employing gelatine [37, 62], proteins [63] and other polymers [64]. 
Table 2. Applications of Spray-Drying for Encapsulation of Essential Oils

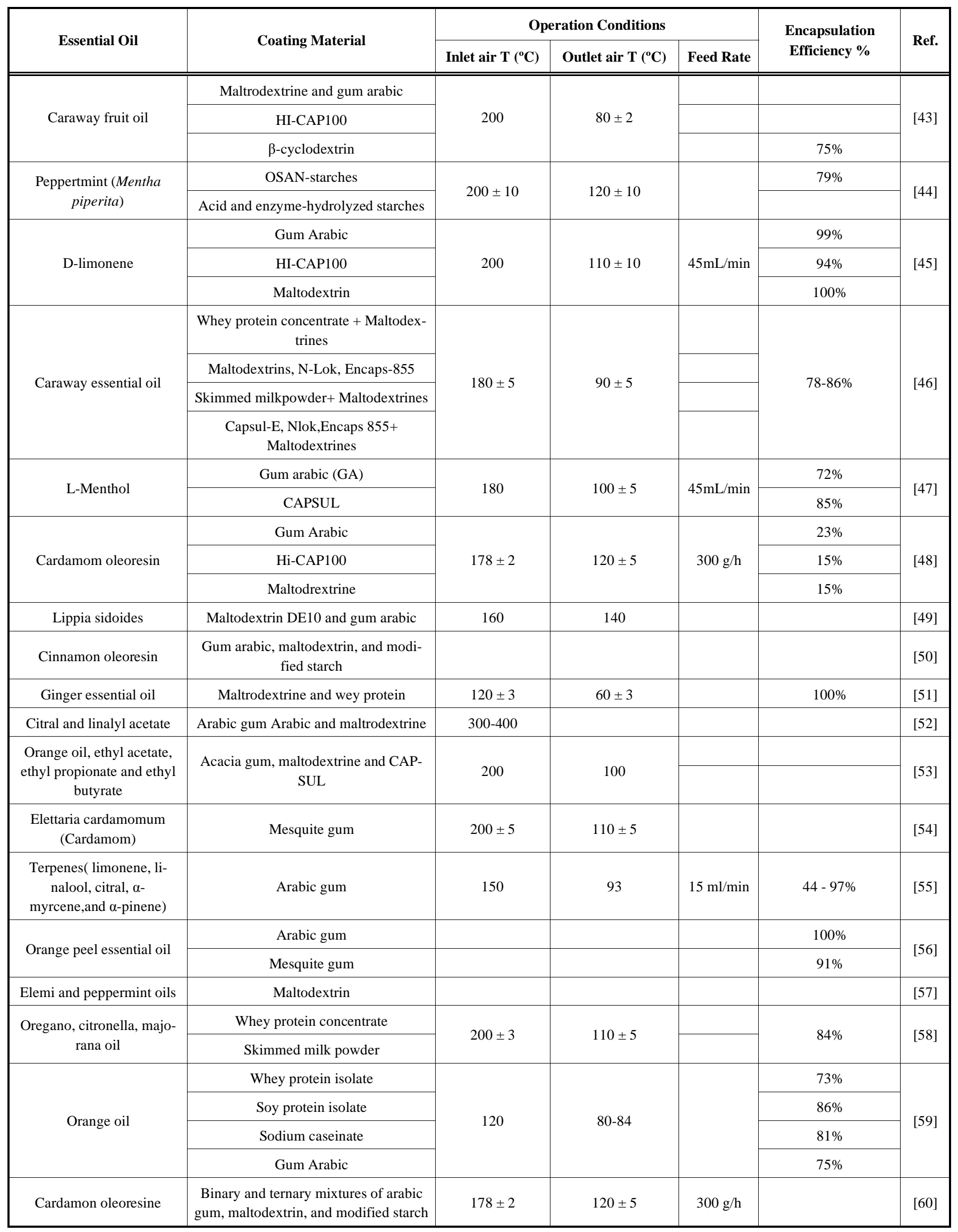


Table 3. Applications of Different Techniques not Based on Supercritical Fluids for Encapsulation of Essential Oils

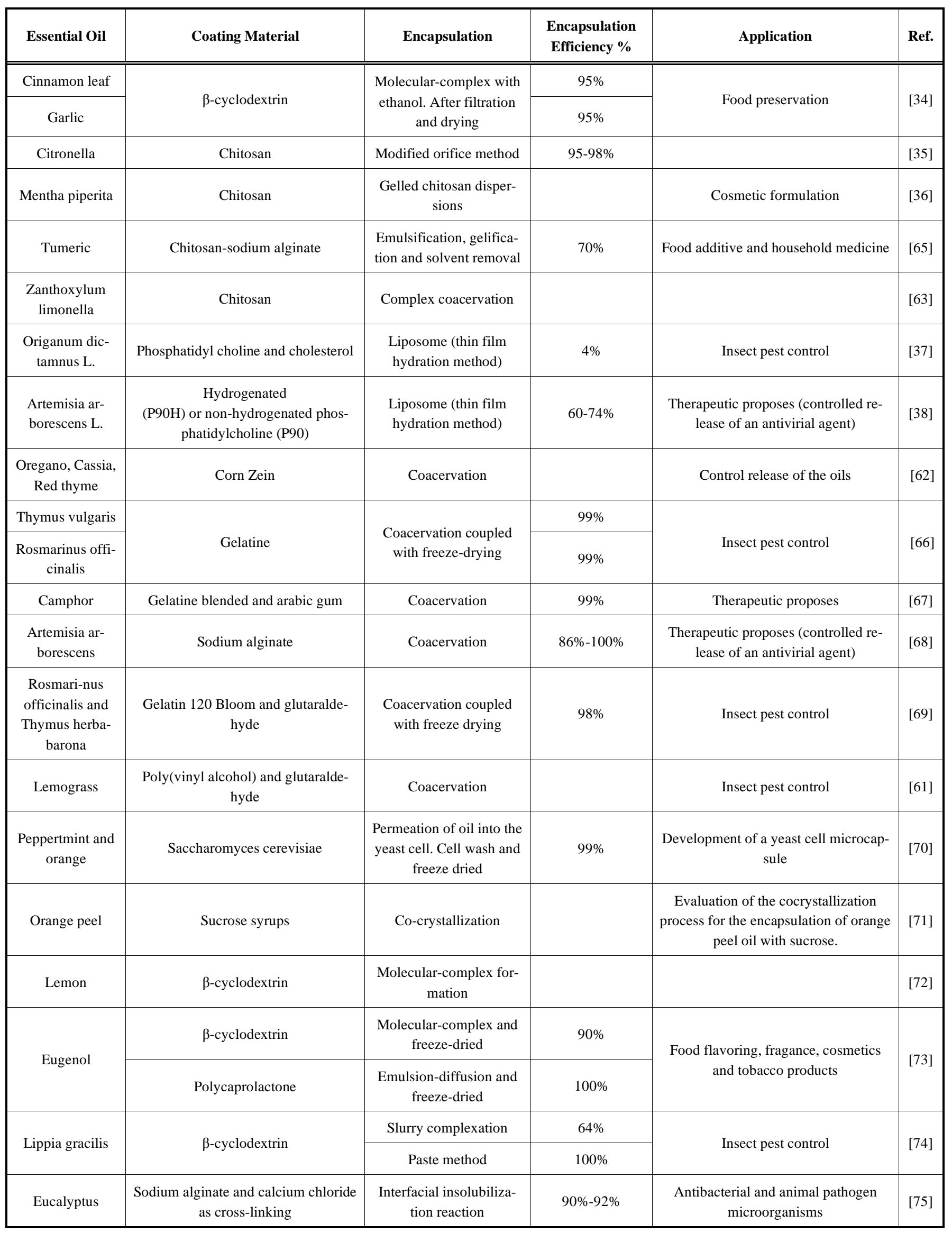




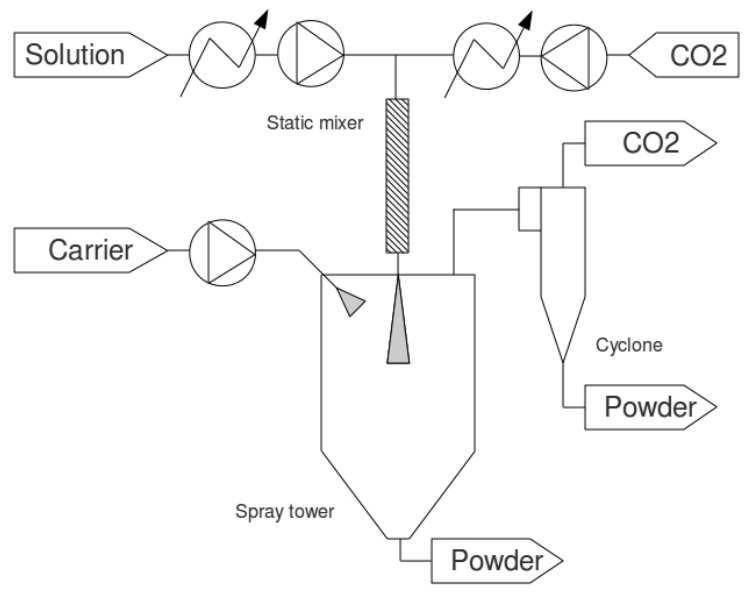

Fig. (1). Schematic diagram of a PGSS process.

\section{APPLICATIONS OF SUPERCRITICAL FLUIDS FOR FORMULATIONS WITH ESSENTIAL OILS}

\subsection{Co-Precipitation and Encapsulation Processes}

Particle formation has been one of the most active fields of research related to supercritical fluids in the last years. Many different precipitation processes based on the use of supercritical fluids have been proposed, in which the supercritical fluids performs different functions as solvent (Rapid Expansion of Supercritical Solutions, RESS), antisolvent (Supercritical Anti Solvent precipitation, SAS), co-solvent or solute (Particles from Gas Saturated Solutions PGSS), propellant (Carbon dioxide-Assisted Nebulisation with a Bubbler Dryer CAN-BD), etc. [28, 76]. Most of these processes were originally developed for producing solid composites, but with some modifications some of them can be used to obtain solid-liquid composites such as essential oil-loaded microcapsules.

In particular, the PGSS process has been adapted for producing solid-liquid composites with promising results. The PGSS process is based on the high solubility of supercritical carbon dioxide in many molten fats, lipids or polymers at moderate pressures (e.g. up to $30 \mathrm{wt} \%$ in poly ethylene glycol -PEG- with $\mathrm{P}<30 \mathrm{MPa}$ [77]). PGSS is a two-step process, as presented in the flow diagram shown in Fig. (1). The first step consists in the saturation of the solute with carbon dioxide, which is accomplished in a static mixer operating at high pressure. The second step consists in expanding the gas saturated solution (typically down to atmospheric pressure) through a nozzle. Joule-Thomson effect induces a pronounced and fast reduction in temperature, which causes particle formation [78]. The PGSS process can be used to encapsulate liquids if the liquid to be encapsulated (e.g., an essential oil) is admixed together with the coating material and $\mathrm{CO}_{2}$ into the static mixer. With this, an emulsion of the essential oil into the gas-saturated coating material is formed in the static mixer and the coating material becomes solid during the expansion, encapsulating the essential oil. The PGSS process has been successfully used to produce solid capsules filled with different liquids [79]. Varona et al. [80] used this technology to produce particles of PEG filled with lavandin essential oil. Encapsulation efficiencies of up to $66 \%$ were achieved and spherical microcapsules of sizes ranging between 80 and $130 \mu \mathrm{m}$ could be obtained.

Another modification of the PGSS process which is suitable for producing liquid-loaded microcapsules is PGSSdrying [78]. The flow diagram of a PGSS-drying process is very similar to that of a conventional PGSS. The main difference between the two techniques is that in PGSS-drying the coating material is fed to the static mixer in an aqueous solution. A certain amount of the gas is dissolved into this solution in the static mixer (higher when the concentration of the coating material in the solution is higher [81]), and the release of this gas from the solution during depressurization considerably enhances solution atomization. Temperature and pressure conditions before the expansion as well as gasto-solution flow ratios have to be chosen in order to ensure that a single fluid phase region is attained after the depressurization and thus dry particles are obtained. PGSS drying can be used to produce liquid-loaded particles if an emulsion is fed to the static mixer. Usually, in this emulsion the liquid to be encapsulated is the organic disperse phase, and the coating material is dissolved in the aqueous continuous phase. With this, the emulsion acts as a template for the particles, whose shape is preserved when the coating material precipitates in the spray. Varona et al. [80] also used this method to produce lavandin oil-loaded microcapsules, in this case using OSA-starches as coating materials. Fifty percent of the oil in the emulsion was encapsulated in the particles. Particle sizes varied between $15 \mu \mathrm{m}$ and $200 \mu \mathrm{m}$, with a residual moisture content of about $5 \%$.

A supercritical fluid-based process which was specifically developed to produce particles loaded with liquids is the Concentrated Powder Form (CPF) process. A schematic flow diagram of a CPF process is shown in Fig. (2): the liquid to be encapsulated is put into contact with a compressed gas, and the gas saturated solution is sprayed through a nozzle. Once again, the release of the gas from the solution dur- 


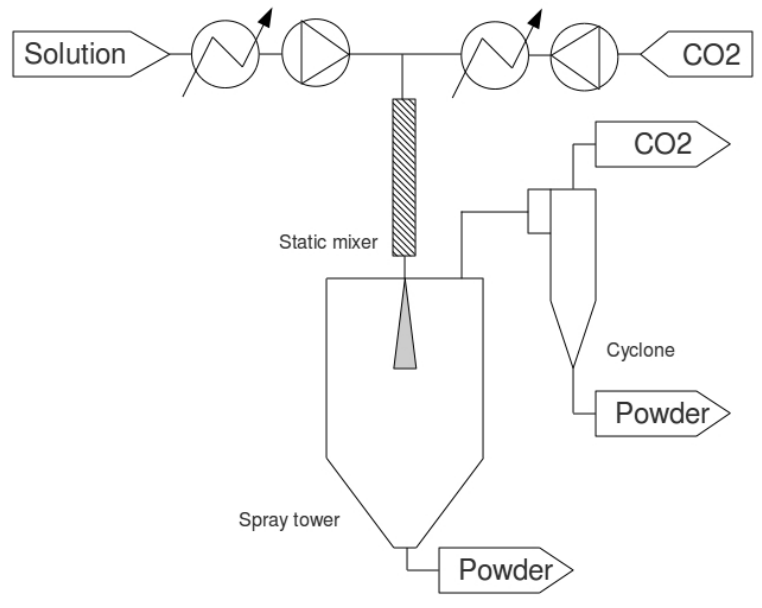

Fig. (2). Schematic diagram of a CPF process.

ing depressurization enhances atomization. After this, previously formed carrier material particles are blown into this spray by means of an inert gas. The two materials are then intensively mixed, and agglomerates of carrier material particles containing high amounts of liquid (up to $90 \mathrm{wt} \%$ ) are obtained [78]. The maximum loading capacity mainly depends on the characteristics of the carrier material particles rather than on the properties of the liquid to be encapsulated [82]. Over 100 liquids have been encapsulated with CPF [78, 83]. This process was applied to encapsulate citrus oil [83], demonstrating that because the process is carried out in inert conditions, no citrus oil degradation products were formed.

Both PGSS and CPF processes are well established technologies with favourable economical conditions for commercial application [78]. They show significant advantages over other formulation processes, including the reduced use of organic solvents, the possibility of operating at moderate temperatures in an inert atmosphere, thus avoiding oxidation or thermal degradation of the essential oil as well as oil losses due to evaporation, and an enhanced control of particle size enabled by the fast precipitation kinetics. Although the reported applications of these technologies for encapsulation of essential oils are not too numerous, the knowledge obtained with the study of the encapsulation of other similar liquids is also relevant for applications with essential oils. Therefore, these technologies are already mature for industrial applications with essential oils.

\subsection{Encapsulation in Micelles and Liposomes}

Water-insoluble substances such as essential oils can be stabilized in an aqueous environment in the inner core of a micelle. Polymeric micelles have been recognised as a very promising carrier for water-insoluble drugs, due to their prolonged stability times in vivo [84]. Therefore they can be suitable formulations for applications of essential oils as antibiotics. The effectiveness of micelle formulations of essential oil active compounds for bacteria growth inhibition has indeed been proved [85]. Although micelles spontaneously form when the concentration of a surfactant or an am- phiphilic block copolymer is higher than the critical micelle concentration, a more elaborate process is required if a high encapsulation efficiency of the oil in the micelle is to be achieved. Nowadays, the most popular micelle production method is to dissolve the active compound and the polymer in an organic solvent, which is then replaced with water by dialysis. This method is adequate for laboratory scale, but has important disadvantages for large scale implementation related to the small productivity of dialysis equipments, and the long processing times required ( $>1$ day). An alternative is the formation of an organic solvent-in-water emulsion followed by the evaporation of the organic solvent, but this approach has his own disadvantages due to the presence of residual organic solvent in the final product and the necessity of exposing the product to high temperatures during prolonged times [86].

A possible alternative is the use of compressed gases or supercritical fluids to remove the organic solvent from the emulsion in order to produce essential oil-loaded micelles, according to the Supercritical Extraction from Emulsions (SFEE) process [87]. A schematic diagram of this process is presented in Fig. (3). It consists in putting the emulsion into contact with a compressed gas. Possible contacting devices include packed columns and sprays. Gas extracts the organic solvent and an aqueous suspension is obtained.

In a recent study performed with the objective of precipitating $\beta$-carotene from the organic phase of a dichloromethane-in-water emulsion [88], it was demonstrated that with this technique it is possible to eliminate the organic solvent from the emulsion down to concentrations below 1 ppm. With a study of the evolution of drop sizes with time, it was shown that final particle size matched the particle size of empty micelles in the initial emulsion. Therefore, it could be concluded that the produced $\beta$-carotene particles were encapsulated in surfactant micelles. The feasibility of carrying out the process at moderate pressures $(5 \mathrm{MPa})$ was also demonstrated. Due to this, this process in principle is also feasible for obtaining micelles loaded with active com- 


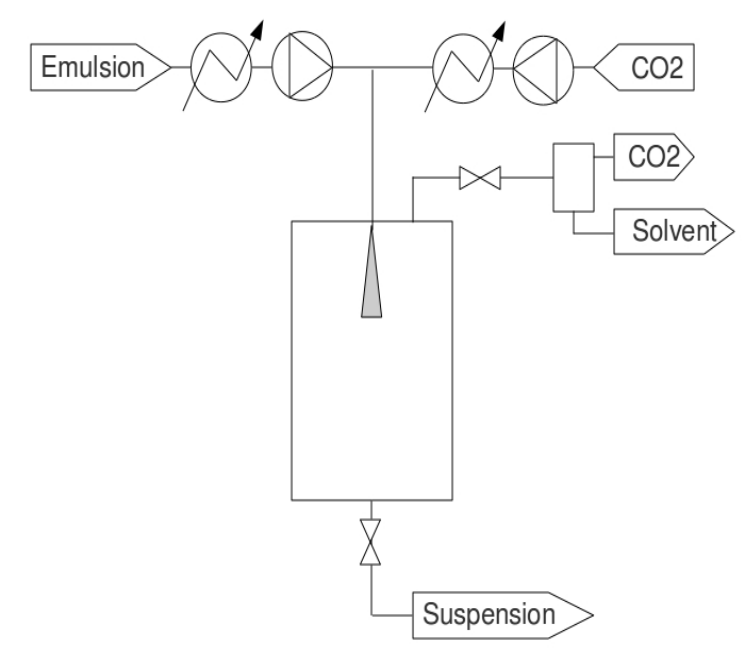

(a)

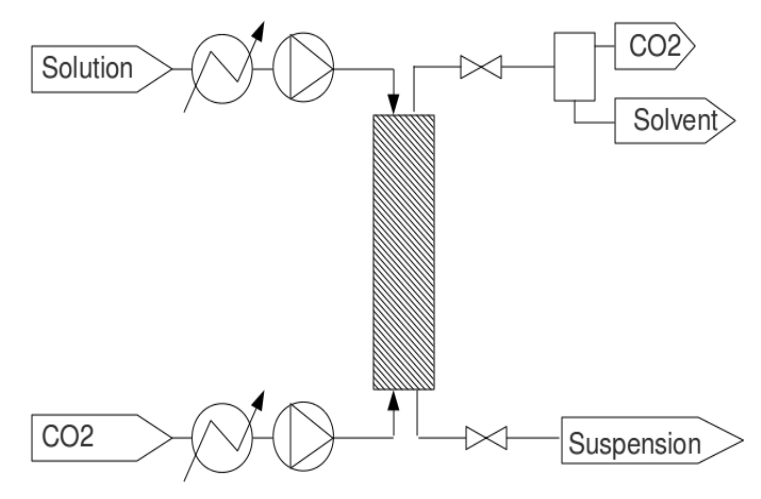

(b)

Fig. (3). Schematic diagram of the Supercritical Fluid Extraction from Emulsions process, (a) using a spray as contacting device and (b) using a packed column.

pounds extracted from essential oils: the solubility of many essential oil compounds in carbon dioxide at moderate pressures is much lower than that of organic solvents (e.g. at 7 $\mathrm{MPa}$ and $313 \mathrm{~K}$, the solubility of linalool, a typical essential oil component, in supercritical carbon dioxide is approximately $1 / 25$ of that of hexane $[89,90])$, and in any case the fraction of essential oil compound extracted during micelle formation can be easily recovered and recycled by depressurization of the gas effluent. Still the experimental validation of this approach has not been carried out.

Liposomes also are promising carriers for essential oils. The antimicrobial and antiviral activity of liposomes loaded with some essential oils has already been proved [37, 38]. An extensive review of conventional and dense gas-based methods for producing liposomes was presented by Meure et al. [91].

Two of the oldest dense-gas techniques for the production of liposomes are the injection and the decompression methods presented by Castor and Chu [92], which are suitable for incorporating hydrophobic compounds such as es- sential oils into the liposomes. In the injection method, the lipid is dissolved into $\mathrm{CO}_{2}$ with the aid of cosolvents and then decompressed into water, while in the decompression method a biphasic $\mathrm{CO}_{2}$-cosolvent-lipid + water mixture is sprayed. Hydrophilic substances to be encapsulated are included in the water phase, and hydrophobic substances in the $\mathrm{CO}_{2}$-cosolvent-lipid phase. Liposomes of less than $200 \mathrm{~nm}$ incorporating hydrophilic and hydrophobic drugs have been produced with this technique, and in vivo tests demonstrated the therapeutic activity of the formulation [93].

Otake et al. [94] developed the so-called "Improved Supercritical Reverse-Phase Evaporation Method" for the production of liposomes. In this method a dispersion of the lipid in water with the substances to be encapsulated was prepared in a batch stirred vessel and $\mathrm{CO}_{2}$ was injected up to the operating pressure (typically $20 \mathrm{MPa}$ ). This mixture was stirred during a certain time to ensure homogenization (approximately for $40 \mathrm{~min}$ ) and then pressure was slowly released to obtain the liposomes. The use of $\mathrm{CO}_{2}$ enabled additional stability of the liposomes due to the formation of carbonic acid by dissolution of $\mathrm{CO}_{2}$ in the water phase, which was incorporated in the liposomes membrane producing a static repulsion effect. Indeed, it was found that the liposomes produced by this technique were stable during more than 30 days, while liposomes produced by other techniques not based on supercritical carbon dioxide were only stable for a few hours. As in the case of micelles, essential oil-loaded liposomes have not yet been produced using supercritical fluids, but previous results obtained with other substances are promising and demonstrate that there are possibilities for applications with essential oils.

In addition to a direct one-step fabrication of the liposomes, some researches have suggested to produce particles of phospholipids loaded with the active compounds of interest as dry precursors of liposomes which can then be reconstituted by hydration. Several supercritical fluid technologies have been used for this purpose, as for example the Supercritical Anti Solvent process (SAS) or the Aerosol Solvent Extraction System (ASES) [95]. Thus the methods described in Section 4.1 are in principle suitable to produce microcapsules of phospholipids loaded with essential oils which can be used as liposome precursors.

\section{CONCLUSIONS}

The use of dense gases and supercritical fluids for the preparation of essential-oil microcapsules is advantageous for several reasons: product degradation or contamination with toxic organic solvents is minimized, in some occasions supercritical fluid processes allow for a enhanced control of product characteristics, a closed and inert system is used for the precipitation which can be easily made compliant with Good Manufacturing Practices, and moreover successful implementations in pilot scale indicate that supercritical precipitation processes present promising technical and economical conditions for large scale production. Several supercritical precipitation processes such as PGSS, PGSS-drying and $\mathrm{CPF}$ have already been successfully used to produce essential-oil loaded microparticles. Even though the number of applications with essential oils studied with these processes is relatively small, the satisfactory results with essential oils as well as with many other similar liquids demon- 
strate good perspectives for the commercial application of these techniques. More recent developments include the preparation of micelles and liposomes with supercritical fluids. Although promising results have been obtained with other hydrophobic substances, the application of these techniques for preparation of formulations with essential oils is still a pending task.

\section{ACKNOWLEDGEMENTS}

Partially financed by Junta de Castilla y León (Project GR11), and Diputación Provincial Valladolid. S. Varona thanks the Valladolid University for a FPI-UVa grant.

\section{REFERENCES}

[1] Report of the international expert consultation on non-wood forest products. Food and Agriculture Organization of the United Nations (FAO). Rome, 1995.

[2] H.J. Dorman, and S.G. Deans, "Antimicrobial agents from plants: antibacterial activity of plant volatile oils", J. Appl. Microbiol., vol. 88, no. 2, pp. 308-316, 2000.

[3] G.J.E. Nychas, Natural Antimicrobials from Plants, New York: Chapman \& Hall, 1995.

[4] S Burt. "Essential oils: their antibacterial properties and potential applications in foods-a review", Int. J. Food Microbiol., vol. 94, no. 3, pp. 223-253, 2004.

[5] N.Y.O. Muyima, G. Zulu, T. Bhengu, and D. Popplewell, "The potential application of some novel essential oils as natural cosmetic preservatives in an aqueous cream formulation", Flavour Frag. J., vol. 17, no. 4, pp. 258-266, 2002.

[6] C. F. Carston, L. Ashton, L. Dry, D. W. Smith, and T. V. Riley, "Melaluca alternifolia (tea tree) oil gel (6\%) for the treatment of recurrent herpes labialis", J. Antimicrob. Chemother., vol. 48, pp. 450-451, 2001.

[7] L. O. Orafidiya, E. O. Albani, A. O. Ovedele, O. O. Babalola, and O. Onayemi, "Preliminary clinical tests on topical preparations of Ocimum Gratissimum Linn leaf essential oil for the treatment of acne vulgaris", Clin. Drug Invest., vol. 22, pp. 313-319, 2002.

[8] S. Ilsley, H. Miller, H. Greathead, and C. Kamel, "Herbal sow diets boost pre-weaning growth", Pig Progress, vol. 18, no. 4, pp. 8-10, 2002.

[9] P. Aertgeerts, M. Albring, F. Klaschka, T. Masemann, R. PatzetlWenczler, K. Rauhut, and B. Weigl, "Comparative testing of Kamillosan cream and steroidal $(0,25 \%$ hydrocortisone, $0,75 \%$ fluocortin butyl ester) and non-steroidal (5\% bufexamac) dermatologic agents in maintenance therapy of eczematous diseases", Z. Hautkrankheiten, vol. 60, no. 3, pp. 270-277, 1985.

[10] R. Carle, and K. Gomaa, "Chamomile: a pharmacological and clinical profile", Drug Today, vol. 28, pp. 559-565, 1992.

[11] S. Bayoumi, "Bacteriostatic effect of some spices and their utilization in the manufacture of yoghurt", Chem. Mikrobiol. Technol. Lebensm., vol 14, pp. 21-26, 1992.

[12] C.L. Wilson, J.M. Solar, A. El. Ghaouth, and M.E. Wisniewski, "Rapid evaluation of plant extracts andeEssential oils for antifungal activity against Botrytis Cinerea", Plant Dis. vol. 81, no. 2, pp. 204-210, 1997.

[13] S.C. Chao, D.G. Young, and C.J. Oberg, "Screening for inhibitory activity of essential oils on selected bacteria, fungi and viruses", $J$. Essent. Oil Res., vol. 12, no. 5, pp.639-649, 2000.

[14] A. K. Mishra, and N. K. Dubey, "Evaluation of some essential oils for their toxicity agains fungui causing deterioration of stored food commodities", Appl. Environ. Microbiol. vol. 60, no. 5, pp. 11011105, 1994.

[15] R. Pandey, A. Kalra, S. Tandon, N. Mehrotra, H. N. Singh, and S. Kumar, "Essential oils as potent source of nematicidal compounds", J. Phytopathol., vol. 148, no. 7-8, pp. 501-502, 2000.

[16] A.M. Maccioni, C. Anchisi, A. Sanna, C. Sardu, and S. Dessi, "Preservative systems containing essential oils in cosmetic products", Int. J. Cosmet. Sci., vol. 24, no. 11, pp. 53-59, 2002.

[17] J. Bruneton, Pharmacognosy, Phytochemistry, Medicinal Plants, Paris: Lavoisier Publishing, 1999.

[18] H.-M. Kim, and S.-H. Cho, "Lavender oil inhibits immediate - type allergic reaction in mice and rats", J Pharm. Pharmacol., vol. 51, pp. 221-226, 1999.
[19] R. Montes-Belmont, and M. Carvajal, "Control of Aspergillus flavus in maize with plant essential oils and their components", $J$. Food Prot., vol. 61, pp. 616-619, 1998.

[20] K. Koutsoumanis, K. Lambropoulou, and G.-J. E. Nychas, "A predictive model for the non-thermal inactivation of Salmonella enteritidis in a food model system supplemented with a natural antimicrobial", Int. J. Food Microbiol., vol. 49, pp. 63-74, 1999.

[21] M. B. Isman, "Botanical insecticides, deterrents, and repellents in modern agriculture and an increasingly regulated world", Апnи. Rev. Entomol., vol. 51, pp. 45-68, 2006.

[22] M. J. Mendoza-Yepes, L. E. Sanchez-Hidalgo, G. Maertens, and F. Marin-Iniesta. "Inhibition of Listeria monocytogenes and other bacteria by a plant essential oil (DMC) in Spanish soft cheese", $J$. Food Saf., vol. 17, pp. 47- 55, 1997.

[23] P. Schnitzler, K. Schön, and J. Reichling, "Antiviral activity of Australian tea tree oil and eucalyptus oil against herpes simplex virus in cell culture", Die Pharmazie, vol. 56, no. 4, pp. 343-347, 2001.

[24] L. Maistrello, M. Lodesani, C. Costa, F. Leopardi, G. Marani, M. Caldon, F. Mulinelli, and A. Granato, "Screening of natural compounds for the control of nosema disease in honeybees (Apis mellifera)", Apidologie, vol. 39, pp. 436-445, 2008.

[25] N. Paster, B.J. Juven, E. Shaaya, M. Menasherov, R. Nitzan, H. Weisslowicz and U. Ravid, "Inhibitory effect of oregano and thyme essential oils on moulds and foodborne bacteria", Lett. Appl. Microbiol., vol. 11, pp. 33-37, 1990.

[26] L. Maistrello, G. Henderson, and R. A. Laine, "Efficacy of vetiver oil and nootkatone as soil barriers against Formosan subterranean termite (Isoptera: Rhinotermitidae)", J. Econ. Entomol., vol. 94, pp. 1532-1537, 2001.

[27] G. Brunner, Gas Extraction, Berlin: Springer, 1994.

[28] M. J. Cocero, A. Martín, F. Mattea, and S. Varona, "Encapsulation and co-precipitation processes with supercritical fluids: fundamentals and applications", J. Supercrit. Fluids, vol. 47, no. 3, 99. 546$555,2009$.

[29] I. Kikic, "Polymer - supercritical fluid interactions", J. Supercrit. Fluids, vol. 47, no. 3, pp. 458-465, 2009.

[30] C. Turchiuli, M. Fuchs, M. Bohin, E. Cuvelier, C. Ordonnaud, M.N. Peyrat-Maillard, and E. Dumoulin. "Oil encapsulation by spray drying and fluidised bed agglomeration", Innov. Food Sci. Emerg. vol. 6, no.1, pp. 29-35, 2005.

[31] R. Partanen, M. Ahro, Mari Hakala, H. Kallio, and P. Forssell. "Microencapsulation of caraway extract in $\beta$-cyclodextrin and modified starches", Eur. Food Res. Technol., vol. 214, pp. 242-247, 2002.

[32] A. Soottitantawata, K. Takayamaa, K. Okamuraa, D. Muranakaa, H. Yoshiia, T. Furutaa, M. Ohkawarab, and P Linkoc. "Microencapsulation of l-menthol by spray drying and its release characteristics", Innov. Food Sci. Emerg., vol. 6, no. 2, pp.163-170, 2005.

[33] S. Varona, A. Martín, and M. J. Cocero. "Formulation of a natural biocide based on lavandin essential oil by emulsification using modified starches", Chem. Eng. Proc., vol. 48, no. 6, pp. 1121$1128,2009$.

[34] J.F. Ayala-Zavala, H. Soto-Valdez, A. Gónzalez-León, E. ÁlvarezParrilla, O. Martín-Belloso, and G.A. González-Aguilar. "Microencapsulation of cinnamon leaf (Cinnamomum zeylanicum) and garlic (Allium sativum) oils in $\beta$-cyclodextrin", J. Inclusion. Phenom. Macrocycl. Chem., vol. 60, pp. 359-368, 2008.

[35] W.C. Hsieh, C.P. Chang, and Y.L. Gao. "Controlled release properties of chitosan encapsulated volatile citronella oil microcapsules by thermal treatments", Colloid. Surface B, vol. 53, pp. 209-214, 2006.

[36] C. Anchisi, M.C. Meloni, and A.M. Maccioni. "Chitosan beads loaded with essential oils in cosmetic formulations", J. Cosmet. Sci., vol. 57, pp. 205-214, 2006.

[37] C. Sinicoa, A.O. De Logub, F. Laia, D. Valentia, M. Manconia, G. Loy, L. Bonsignore, and A. M. Fadda. "Liposomal incorporation of Artemisia arborescens L. essential oil and in vitro antiviral activity", Eur. J. Pharm. Biopharm., vol. 59, pp. 161-168, 2005.

[38] C.C. Liolios, O. Gortzi, S. Lalas, J. Tsaknis, and I. Chinou. "Liposomal incorporation of carvacrol and thymol isolated from the essential oil of Origanum dictamnus L. and in vitro antimicrobial activity", Food Chem., vol. 112, pp. 77-83, 2009.

[39] B. F.Gibbs, S. Kermasha, I. Alli, and C. N. Mulligan. "Encapsulation in the food industry: a review", Int. J. Food Sci. Nutr., vol. 50, pp. 213-224, 1999. 
[40] A. Gharsallaoui, G. Roudaut, O. Chambin, A. Voilley and R. Saurel. "Applications of spray-drying in microencapsulation of food ingredients: an overview", Food Res. Int., vol. 40, pp. 1107-1121, 2007.

[41] L. Alamilla-Beltrán, J.J. Chanona-Pérez, A.R. Jiménez-Aparicio, and G.F. Gutiérrez-López. "Description of morphological changes of particles along spray drying", J. Food Eng., vol. 67, pp. 179$184,2005$.

[42] A.A. Dolinsky. "High-temperature spray drying", Dry. Technol. vol. 19, no. 5, pp. 785-806, 2001.

[43] R. Partanen, M. Ahro, Mari Hakala, H. Kallio, and P. Forssell. "Microencapsulation of caraway extract in $\beta$-cyclodextrin and modified starches", Eur. Food Res. Technol., vol. 214, pp. 242-247, 2002.

[44] R. Baranauskiené, E. Bylaitè, J. Zukauskaite, and R. Flavor, "Retention of Peppermint (Mentha piperita L.) essential oil spray-dried in modified starches during encapsulation and storage", J. Agric. Food Chem., vol. 55, pp. 3027-3036, 2007.

[45] A. Soottitantawat, F. Bigeard, H. Yoshii, T. Furuta, M. Ohkawara, and P. Linko. "Influence of emulsion and powder size on the stability of encapsulated D-limonene by spray drying", Innov. Food Sci. Emerg., vol. 6, pp. 107-114, 2005.

[46] E. Bylaitë, P. R. Venskutonis, and R. Mapdpierienë. "Properties of caraway (Carum carvi L.) essential oil encapsulated into milk protein-based matrices", Eur. Food Res. Technol., vol. 212, pp. 661670, 2001.

[47] A. Soottitantawata, K. Takayamaa, K. Okamuraa, and D. Muranakaa. "Microencapsulation of 1-menthol by spray drying and its release characteristics", Innov. Food Sci. Emerg., vol. 6, pp. 163-170, 2005.

[48] S. Krishnan, A. C. Kshirsagar, R. S. Singhal. "The use of gum arabic and modified starch in the microencapsulation of a food flavoring agent", Carbohydr. Polym., vol. 62, pp. 309-315, 2005.

[49] L.P. Fernandes, I.C.C. Turatti, N.P. Lopes, J.C. Ferreira, R.C. Candido, and W.P. Oliveira . "Volatile retention and antifungal properties of spray-dried microparticles of lippia sidoides essential oil", Drying Technol., vol. 26, no. 12, pp. 1534-42, 2008.

[50] S. Vaidya, R. Bhosale, and R. Singhal, "Microencapsulation of cinnamon oleoresin by spray drying using different wall materials", Drying Technol., vol. 24, no. 8, pp. 983-992, 2006.

[51] A. Toure, Z. Xiaoming, C.S. Jia, D. Zhijian, "Microencapsulation and oxidative stability of ginger essential oil in maltodextrine/whey protein isolate (MD/WPI)", Int. J. Dairy Technol., vol. 2, no. 4, pp. 387-392, 2007.

[52] B.R. Bhandari, E.D. Dumoulin, H.M.J. Richard, I. Noleau, A.M. Eberet, "Flavor encapsulation by spray drying: application to citral and linalyl acetate", J. Food Sci., vol. 57, pp. 217-221, 2006.

[53] R.A. Buffo, K. Probst, G. Zehentbauer, Z. Luo, and G.A. Reineccius, "Effects of agglomeration on the properties of spray-dried encapsulated flavours", Flavour Fragrance J. vol. 17, pp. 292-299, 2002.

[54] C.L. Beristain, H.S. Garcm, and E.J. Vernon-Carter, "Spray-dried Encapsulation of Cardamom (Elettaria cardamomum) Essential Oil with Mesquite (Prosopis juli-ora) Gum", Lebensm Wiss. Technol., vol. 34, pp. 398:401, 2001.

[55] A.C. Bertolini, A.G. Siani, and C.R.F. Grosso, "Stability of monoterpenes encapsulated in gum arabic by spray-drying", J. Agric. Food Chem., vol. 49, no. 2, pp. 780-785, 2001.

[56] F.M. Goycoolea, A.M. Calderon De La Barca, J.R. Balderrama, J.R. Valenzuela, "Immunological and functional properties of the exudate gum from northwestern mexican mesquite (prosopis spp.) in comparison with gum Arabic", Int. J. Biol. Macromol., vol. 21, no. 1-2, pp. 29-36, 1997.

[57] J. Adamiec, D. Kalemba, "Analysis of microencapsulation ability of essential oils during spray drying." Drying Technol., vol. 24, no. 9, pp. 1127-1132, 2006.

[58] R. Baranauskieniené, P. R. Venskutonis, K. Dewettinck, R. Verhe, Properties of oregano (Origanum vulgare L.), citronella(Cymbopogon nardus G.) and marjoram (Majorana hortensis L.)flavors encapsulated into milk protein-based matrices", Food Res. Int. vol. 39, pp. 413-425, 2006.

[59] Y.D. Kim, and C.V. Morr, "Microencapsulation properties of gum Arabic and several food proteins: spray-dried orange oil emulsion particles", J. Agric. Food Chem., vol. 44, pp. 1314-1320, 1996.

[60] S. Krishnan, R. Bhosale, R.S. Singhal, "Microencapsulation of cardamom oleoresin: evaluation of blends of gum arabic, maltodex- trin and a modified starch as wall materials", Carbohydr. Polymer, vol. 61, pp. 95-102, 2005.

[61] F. V. Leimann, O. H. Gonçalves, R. A.F. Machado, and A. Bolzan, "Antimicrobial activity of microencapsulated lemongrass essential oil and the effect of experimental parameters on microcapsules size and morphology", Mater. Sci. Eng. C, vol. 29, no. 2, pp. 430-436, 2009.

[62] N. Parris, P.H. Cooke, K.B. Hicks, "Encapsulation of Essential oils in Zein Nanospherical Particles", J. Agric. Food Chem., vol. 53, pp. 4788-4792, 2005.

[63] M.R. Hussain, and T.K. Maji. "Preparation of genipin cross-linked chitosan-gelatin microcapsules for encapsulation of Zanthoxylum limonella oil (ZLO)using salting-out method", J. Microencapsulation, vol. 25, no. 6, pp. 414-420, 2008.

[64] A.H. Faraji, and P. Wipf, "Nanoparticles in cellular drug delivery", Bioorg. Med. Chem., vol. 17, pp. 2950-2962, 2009.

[65] P. Lertsutthiwong, P. Rojsitthisak, and U. Nimmannit, "Preparation of turmeric oil-loaded chitosan-alginate biopolymeric nanocapsules”, Mater. Sci. Eng. C, vol. 29, pp. 856-860, 2009

[66] G. Sanna Passino, E. Bazzoni, and M.D. Moretti. "Microencapsulated essentials oils active agains indianmeal moth2. Bol. San. Veg. Plagas, vol. 30, pp. 125-132, 2004.

[67] C.P. Chang, T.K. Leung, S.M. Lin, C.C. Lin, "Release properties on gelatin-gum arabic microcapsules containing camphor oil with added polystyrene", Colloid. Surf. B: Biointerfaces, vol. 50, pp. 136-140, 2006.

[68] F. Lai, G. Loy, M. Manconi, M.L. Manca, and A. Maria Fadda, "Artemisia arborescens L essential oil loaded beads: preparation and characterization", AAPS PharmSciTech vol. 8, no. 3, Article 67, pp. E1-E7, 2007.

[69] M. D.L. Moretti, G. Sanna-Passino, S. Demontis, E. Bazzoni, "Essential oil formulations useful as a new tool for insect pest control", AAPS PharmSciTech vol. 3, no. 2, Article 13, pp. 1-11, 2002.

[70] J.R. Bishop, Nelson G, and J. Lamb, "Microencapsulation in yeast cells", J. Microencapsulation, vol. 15, no. 6 pp. 761-773, 1998.

[71] C.I. Beristain, A. Vazquez, H.S. Garcia, and E.J. Vernon-Carter, "Encapsulation of orange peel oil by co-crystallization", Lebensm.Wiss. u.-Technol., vol. 29, pp. 645-647, 1996.

[72] P. Indra, B. Bhesh, and D'A. Bruce, "Evaluation of various extraction methods of encapsulated oil from $\mathrm{fl}$-cyclodextrin-lemon oil complex powder", J. Food Comp. Anal., vol. 13, no. 1, pp. 59-70, 2000.

[73] M.J. Choi, A. Soottitantawat, O. Nuchuchua, S.G. Min, and U. Ruktanonchai, "Physical and light oxidative properties of eugenol encapsulated by molecular inclusion and emulsion-diffusion method", Food Res. Int. vol. 42, no. 148-156, 2009.

[74] C. P. Chang, and T. Dobashi, "Preparation of alginate complex capsules containing eucalyptus essential oil and its controlled release", Colloid. Surf. B, vol. 32, pp. 257-262, 2003.

[75] R. N. Marreto, E. E.C.V. Almeida, P. B. Alves, E. S. Niculau, R.S. Nunes, C. R.S. Matos, A. A.S. Araújo, "Thermal analysis and gas chromatography coupled mass spectrometry analyses of hydroxypropyl- -cyclodextrin inclusion complex containing Lippia gracilis essential oil", Thermochim. Acta, vol. 475, pp. 53-58, 2008.

[76] A. Martín, and M. J. Cocero. "Precipitation processes with supercritical fluids: patents review", Recent Pat. Eng., vol. 2, no. 1, pp. 9-20, 2008.

[77] E. Weidner, V. Wiesmet, and Z. Knez. "Phase equilibrium (solidliquid-gas) in polyethyleneglycol-carbon dioxide systems", $J$. Supercrit. Fluids, vol. 10, pp. 139-147, 1997.

[78] E. Weidner. "High pressure micronization for food applications", $J$. Supercrit. Fluids, vol. 47, pp. 556-565, 2009.

[79] G. Brandin, "Micro particles filled with liquid using the particles from gas saturated solutions technology", In: AIChE Annual Meeting, Conference Proceedings, San Francisco, California (USA), 2006.

[80] S. Varona, S. Kareth, and M. J. Cocero, "Encapsulation of essentials oils using biopolymers for their use in ecological agriculture", In: proceedings of $9^{\text {th }}$ International Symposium on Supercritical Fluids, Arcachon (France), 2009.

[81] A. Martín, H. M. Pham, A. Kilzer, S. Kareth, and E. Weidner, "Phase equilibria of carbon dioxide + poly ethylene glycol + water mixtures at high pressure: measurements and modelling", Fluid Phase Eq. vol. 286, pp. 50-57, 2009. 
[82] H. Lankes, K. Sommer, and B. Weinreich, "Liquid absorption capacity of carriers in the food technology", Powder Technol., vol. 134, pp. 201-209, 2003.

[83] S. Grüner, F. Otto, and B. Weinreich, "CPF-technology - a new cryogenic spraying process for pulverization of liquids", In: proceedings of the $6^{\text {th }}$ International Symposium on Supercritical Fluids, Versailles, 2003.

[84] M.-C. Jones, and J.-C, "Leroux. Polymeric micelles - a new generation of colloidal drug carriers", Eur. J. Pharm. Biopharm. vol. 48, pp. 101-111, 1999.

[85] S. Gyasinsky, P. M. Davidson, B. D. Bruce, and J. Weiss, "Growth inhibition of Escherichia coli O157:H7 and Listeria monocytogenes by carvacrol and eugenol encapsulated in surfactant micelles", $J$. Food Prot., vol. 68, no. 12, pp. 2559-2566, 2005.

[86] G. Kwon, M. Naito, M. Yokoyama, T. Onaka, Y. Sakurai, and K. Kataoka, "Block copolymer micelles for drug delivery: loading and release of doxorubicin", J. Control Release vol. 48, pp. 195-201, 1997.

[87] B. Y. Shekunov, P. Chattopadhyay, J. Seitzinger, and R. Huff, "Nanoparticles of poorly water-soluble drugs prepared by supercritical fluid extraction of emulsions", Pharm. Res. vol. 23, no. 1, pp. 196-204, 2006.

[88] F. Mattea, A. Martín, A. Matías-Gago, and M. J. Cocero, "Supercritical antisolvent precipitation from an emulsion: $\beta$-carotene nanoparticle formation", J. Supercrit. Fluids, 2009, doi: 10.1016/j.supflu. 2009.08.013.
[89] Y. Hsiao Li, K. H. Dillard, and R. L. Robinson, "Vapor-Liquid phase equilibrium for carbon dioxide - n-hexane at 40, 80 and $120^{\circ}$ C", J. Chem. Eng. Data, vol. 26, pp. 53-55, 1981.

[90] A. Berna, A. Cháfer, and J. B. Montón, "Solubilities of essential oil components of orange in supercritical carbon dioxide", J. Chem. Eng. Data, vol. 45, pp. 724-727, 2000.

[91] L. A. Meure, N. R. Foster, and F. Dehghani, "Conventional and dense gas techniques for the production of liposomes: a review", AAPS PharmSciTech, vol. 9, no. 3, pp.798-809, 2008.

[92] T. P. Castor, and L. Chu, "Methods and apparatus for making liposomes containing hydrophobic drugs", WO patent 9615774 1996.

[93] T. P. Castor. "Phospholipid nanosomes", Curr. Drug Deliv., vol. 2, no. 4, pp. 329-340, 2005.

[94] K. Otake, T. Shimomura, T. Goto, T. Imura, T. Furuya, S. Yoda, Y. Takebayashi, H. Sakai, M. Abe. "One-step preparation of chitosancoated cationic liposomes by an improved supercritical reversephase evaporation method", Langmuir, vol. 22, pp. 4054-4059, 2006.

[95] S. Kunastitchai, L. Pichert, N. Sarisuta, and B. W. Muller. "Application of aerosol solvent extraction system (ASES) process for preparation of liposomes in a dry and reconstitutable form", Int. $J$. Pharm., vol. 316, no. 1-2, pp. 93-101, 2006.

Received: August 12, 2009

(C) Martín et al.; Licensee Bentham Open.

This is an open access article licensed under the terms of the Creative Commons Attribution Non-Commercial License (http://creativecommons.org/licenses/by-nc/3.0/) which permits unrestricted, non-commercial use, distribution and reproduction in any medium, provided the work is properly cited. 